\title{
Supersonic Retropropulsion CFD Validation with Ames Unitary Plan Wind Tunnel Test Data
}

\author{
Daniel G. Schauerhamer (daniel.g.schauerhamer@nasa.gov, 281-483-0528) \\ Jacobs/NASA Johnson Space Center \\ Kerry A. Zarchi (kerry.zarchi@nasa.gov, 650-605-4973) \\ NASA Ames Research Center \\ William L. Kleb (bil.kleb@nasa.gov, 757-812-1805) \\ Karl T. Edquist (karl.t.edquist@nasa.gov, 757-864-4566) \\ NASA Langley Research Center
}

\begin{abstract}
A validation study of Computational Fluid Dynamics (CFD) for Supersonic Retropropulsion (SRP) was conducted using three Navier-Stokes flow solvers (DPLR, FUN3D, and OVERFLOW). The study compared results from the CFD codes to each other and also to wind tunnel test data obtained in the NASA Ames Research Center $9^{\prime} \times 7^{\prime}$ Unitary Plan Wind Tunnel. Comparisons include surface pressure coefficient as well as unsteady plume effects, and cover a range of Mach numbers, levels of thrust, and angles of orientation. The comparisons show promising capability of CFD to simulate SRP, and best agreement with the tunnel data exists for the steadier cases of the 1-nozzle and high thrust 3-nozzle configurations.
\end{abstract}

\section{TABLE OF CONTENTS}

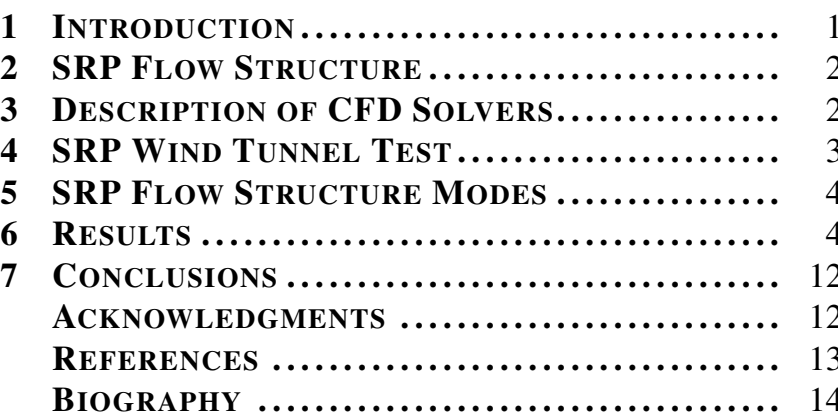

\section{INTRODUCTION}

Supersonic Retropropulsion (SRP) is a potentially viable means to decelerate high mass vehicles entering the Martian atmosphere [1]-[6]. Previous methods of deceleration are not scalable for exploration type vehicles which can potentially weigh tens of metric tons. Since ground and flight testing of SRP at entry conditions can be difficult and cost-prohibitive, the development of this enabling technology can be enhanced with the ability to predict the flowfield numerically using Computational Fluid Dynamics (CFD).

SRP results in a complex flow structure involving shocks, shear layers, recirculation and stagnation regions, which makes validation of the CFD methods a high priority. The validation process includes using multiple CFD codes to compare to historical and recent wind tunnel tests. Three CFD codes are being applied to SRP: DPLR (Data Parallel Line Relaxation) [32], FUN3D (Fully Unstructured Navier-Stokes Three-Dimensional)[33] [34], and OVERFLOW (OVERset

U.S. Government work not protected by U.S. copyright.

1 IEEEAC Paper \#2103, Version 1, Updated 17/10/2012. grid FLOW solver) [35]. The codes all solve the NavierStokes equations, but differ in implementation, grid type, and numerical methods. Through code-to-code and code-totest comparisons, best practices in grid generation, numerical method selection, and solution advancement are established, and validity is added to the CFD methods. With continuing validation, confidence is built for using CFD to predict Mars entry conditions.

CFD validation efforts for SRP were conducted under the NASA Exploration Technology Development Program. The CFD solvers were applied [8] to a historical [7] and a more recent [36] wind tunnel test. Although much was learned through the exercise, the historical test reports lacked key information for CFD validation. A wind tunnel test was then conducted for the purpose of CFD validation in the Langley Research Center supersonic $4^{\prime} \times 4^{\prime}$ Unitary Plan Wind Tunnel (LRC UPWT) [14], the design of which was aided by CFD [12] [13]. Through results from the test, the CFD best practices were established [15] and an extensive comparison study was conducted [16]. The study yielded promising results, but not all conditions were properly predicted consistently between the CFD codes. To further the validation exercise, and to obtain higher and more flight-relevant thrust levels, the same model was tested in the NASA Ames Research Center $9^{\prime} \times 7^{\prime}$ Unitary Plan Wind Tunnel (ARC UPWT). This paper will focus on the subsequent CFD validation study. A subset of the study can be found in reference [17], upon which this paper builds.

Qualitative comparisons of the flow structure will be made by comparing CFD to high-speed shadowgraph images, and quantitative comparisons will be made by comparing averaged surface pressure with pressure tap data from the tunnel. High frequency pressure transducer data are also available, and have been studied more thoroughly for the LRC UPWT test [37] than for the ARC UPWT test. Comparisons of dominant frequencies of certain runs were discussed in references [15] and [17]. Neither test used a balance system, so forces and moments were not measured. However, code-tocode comparisons of forces and moments were included in references [16] and [17].

This paper will first introduce the SRP flow structure, the CFD solvers, and the ARC UPWT test. It will then discuss the different modes the SRP flow structure experiences depending on nozzle configuration, thrust level, angle of attack, and Mach number. Then CFD results are compared to tunnel data, and strengths and weaknesses of the solvers are discussed. 


\section{SRP FLOW STRUCTURE}

Figure 1 shows a CFD simulation of a run from the Daso, et al. wind tunnel test [36] to represent the SRP flow structure. In a supersonic freestream, a bow shock forms around the model, which is an Apollo capsule with an embedded sonic nozzle. As an opposing jet is initiated, the bow shock is pushed upstream as the apparent body frontal area is increased with the appearance of a barrel plume. The barrel plume contains free shear layers as well as a terminal shock. Between the terminal and bow shocks is an interface or contact surface where opposing streams stagnate. With the barrel plume, recirculation regions appear as well as a triple point, where three types of flow meet: supersonic jet flow, subsonic post-shock jet flow, and subsonic recirculating flow. The term "triple point" has a two-dimensional sense to it, in three dimensions it is an annular ring.

This is an example of 1-nozzle SRP flow at a relatively high thrust level. Other modes exist depending on the jet-tofreestream pressure ratios, including a long-jet penetration mode at low pressure ratios [7]. Even other modes exist and can vary according to thrust level, angles of attack, and multiple nozzle configurations where plume-to-plume interactions may exist.

\section{DESCRIPTION OF CFD SOLVERS}

The three solvers applied to the SRP problem differ in implementation, grid type, and numerical methods. DPLR and FUN3D are finite-volume while OVERFLOW is finitedifference. DPLR uses cell-centered structured overset grids, while OVERFLOW uses node-centered structured overset grids. FUN3D employs node-centered unstructured grids. With these differences between codes, much is to be learned through code-to-code comparison when applying them to a single set of problems.

In reference [15], grid and time resolution, observed order of accuracy, and the establishment of best practices are described in detail. The best practices were established through CFD sensitivity studies being applied to a 1-nozzle case from the LRC UPWT test. The following are brief descriptions of each code including the numerical methods used by each in this study.

\section{DPLR}

The DPLR CFD code is a parallel, structured multi-block, finite-volume code with overset grid capability that solves the Reynolds-Averaged Navier-Stokes (RANS) equations for continuum flow, including finite-rate chemistry and thermal non-equilibrium. In the present study, the thermally- and calorically-perfect RANS equations for air are solved implicitly with 1st-order time accuracy. Inviscid fluxes are formed via a modified Steger-Warming flux vector splitting [21] with 3rd-order Monotone Upwind Scheme for Conservation Laws (MUSCL) extrapolation [22] subject to a minmod limiter [23] and 2nd-order flux integration. The viscous terms are computed with a 2 nd-order spatial accuracy central difference approach. For the present analysis, Menter's Shear-Stress Transport (SST) turbulence model [24] was employed with a vorticity-based production term and no compressibility corrections.

\section{FUN3D}

FUN3D contains a node-based finite-volume unstructured flow solver. For this study, FUN3D was run with a

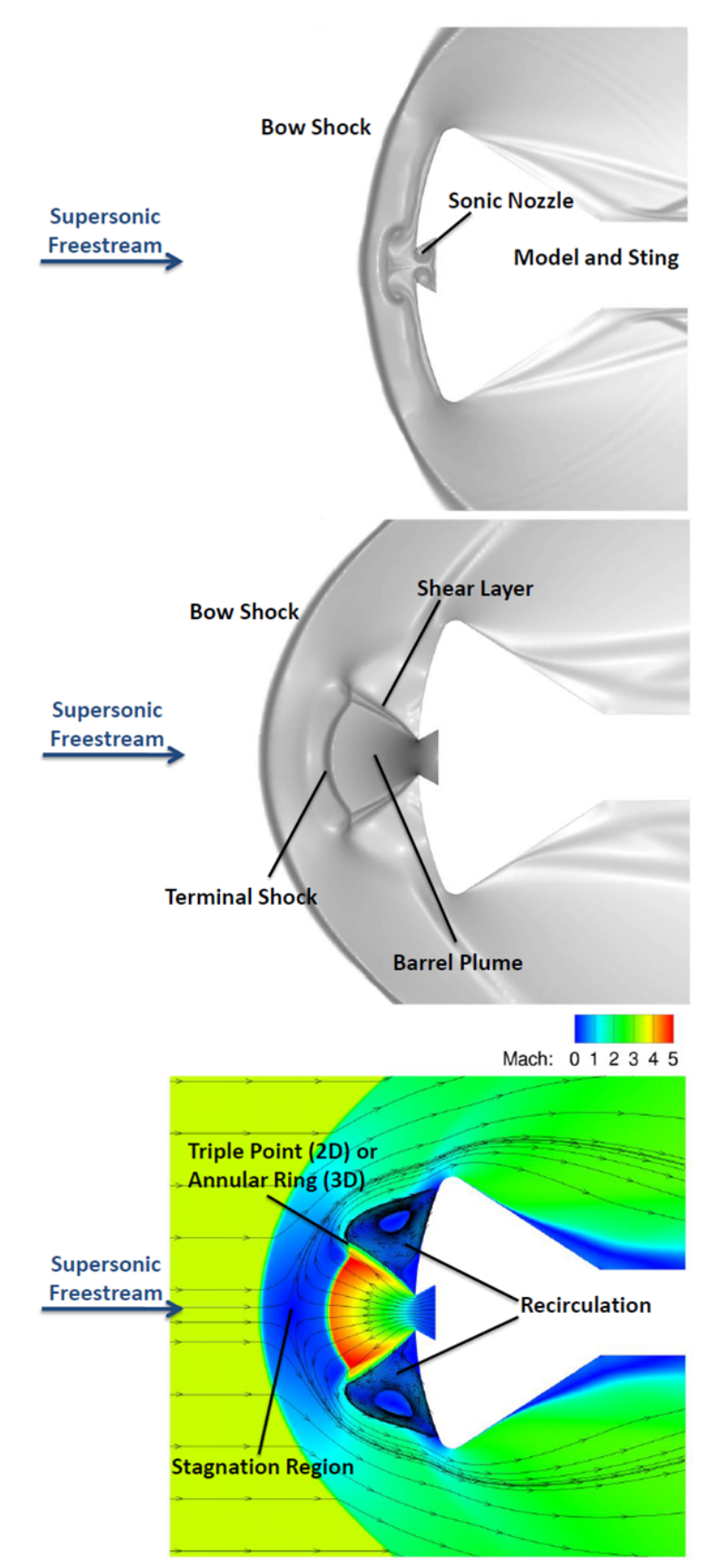

Figure 1. 1-nozzle SRP flow structure description diagrams.

selectively-dissipative version of the Low-Dissipation Flux Splitting Scheme (LDFSS) inviscid flux function [25] and a modified Van Albada [26] limiter according to Vatsa and White [27]. Direct Eddy Simulation (DES) turbulence modeling was used with Spalart-Allmaras (SA) [28] as the submodel. Node-based conservative variables are computed by driving a 2nd-order accurate spatial residual to steady-state with a point-implicit iterative method. A modified, optimum 2nd-order backward difference formula (BDF) scheme is used in conjunction with a temporal error controller that assured design order [29]. 


\section{OVERFLOW}

OVERFLOW 2 is an implicit Navier-Stokes flow solver that uses structured overset grids. For the current work, the HLLE++ numerical flux function [30] with the Van Albada limiter was used for spatial terms, and the Symmetric Successive Over Relaxation (SSOR) algorithm with dual time stepping using Newton sub-iterations for temporal terms. DES turbulence modeling was used with SST as the submodel, the SST model used the strain-based production term and employed Wilcox's realizability constraint [31]. The overall scheme is 2 nd-order accurate in space and time. The calculation of the inviscid fluxes for both the flow solver and the turbulence model use 3rd-order accurate MUSCL reconstruction and 2nd-order flux quadrature.

\section{SRP WIND TUNNEL TEST}

Test 234 in the ARC UPWT was designed specifically for SRP CFD validation and was a follow-on to test 1853 of the LRC UPWT. The reason for the ARC UPWT test was to use the same model from the previous test in a larger test section to be able to obtain higher and more flight-relevant thrust coefficients $\left(C_{T}=T /(q A)\right)$.

The model was a $70^{\circ}$ sphere-cone forebody with a 5 inch diameter cylindrical side body. The model included four nozzles which could be plugged to offer 0-, 1-, 3-, or 4-nozzle configurations. One nozzle was located at the center of the forebody, and the three others were oriented radially every $120^{\circ}$ at the model's $1 / 2$ radius. Air was used as both the freestream and jet gases. The test data included high speed shadowgraph movies (5-10 thousand frames per second) and pressure readings from 167 taps including seven $40 \mathrm{kHz}$ pressure transducers. From these data, qualitative comparisons with CFD flow structure and unsteady behavior can be made with the shadowgraph movies, as well as averaged surface pressure comparisons with the pressure taps.

The test run matrix included four nozzle configurations: 0,1 (center), 3 (peripheral), and 4 (center and peripheral). Two Mach numbers were tested: 1.8 and 2.4. The Reynolds number per foot for Mach 1.8 was 1.5 million, and for Mach 2.4, 1 and 1.5 million were tested. The total freestream temperature for Mach 1.8 was 550 degrees Rankine, and for Mach 2.4 was 555 degrees Rankine. For angles of orientation, $\alpha$ ranged from $-8^{\circ}$ to $20^{\circ}$ and $\beta$ ranged from $0^{\circ}$ to $12^{\circ}$. Thrust coefficients ranged from 0 to 10 in increments of 2 . To mitigate liquefaction, the jet air supply was heated to $150^{\circ} \mathrm{F}$; however, evidence of some liquefaction was noted at high thrust levels. A full description of the test can be found in reference [20]. Figure 2 is a snapshot of the model in the 1-nozzle configuration in the test section. Figure 3 shows diagrams of the model face and side-body pressure tap layouts [19].

Tunnel uncertainty will not be included in this paper since calculations are still underway, but will be carried out with the same method as the LRC UPWT test [19] as described in reference [9].

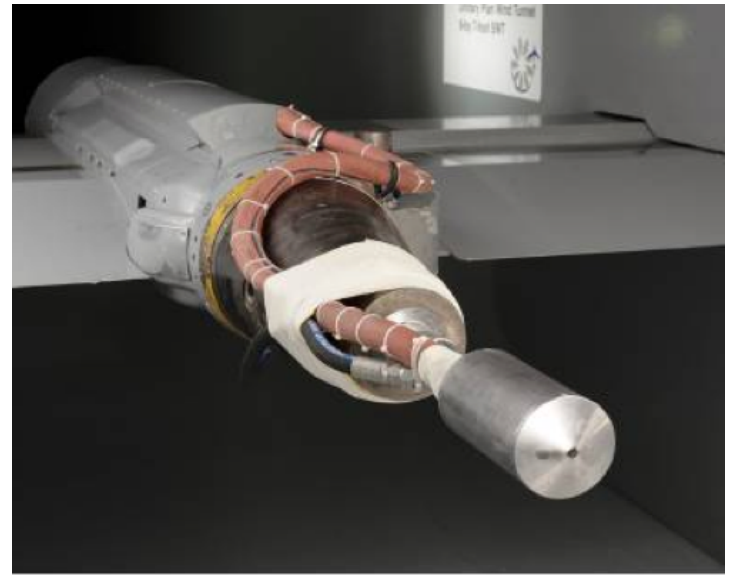

Figure 2. SRP test model in the 1-nozzle configuration in the NASA ARC $9^{\prime} \times 7^{\prime}$ UPWT.

\section{Forebody Instrumentation}
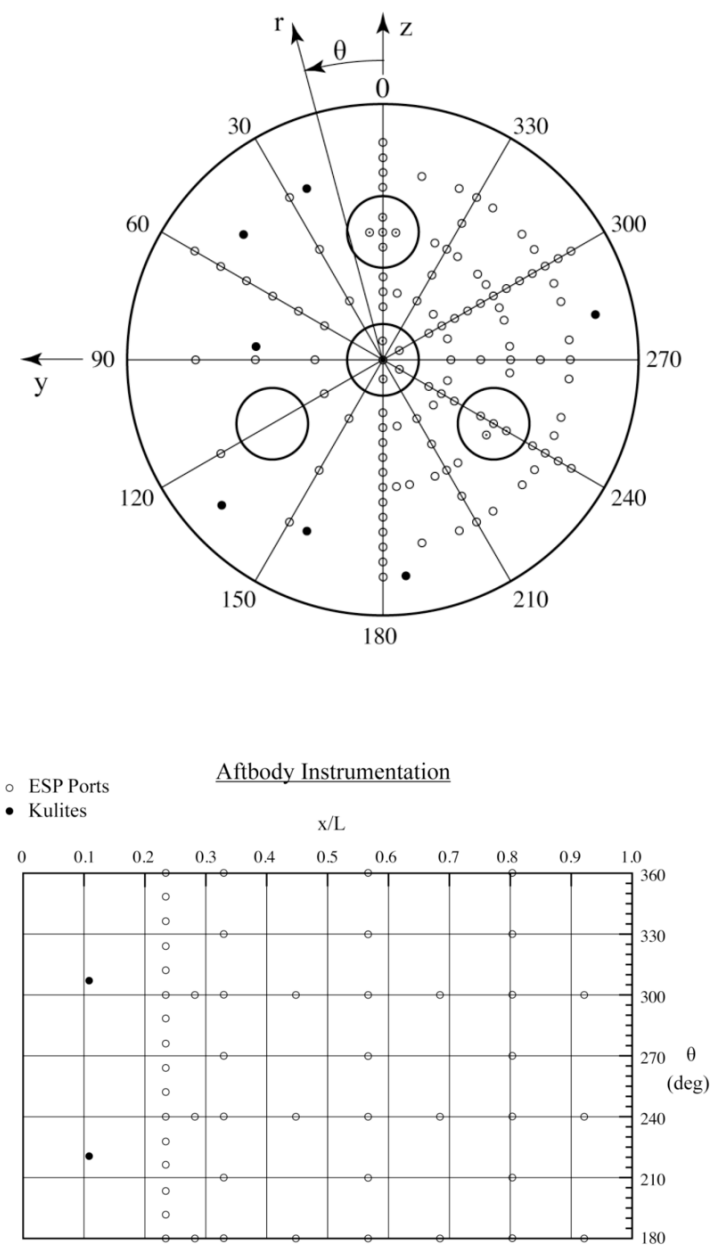

Figure 3. Pressure tap layout on the test model. Top image is the front face of the model and the bottom image is the side body. Filled circles represent the high frequency Kulite ${ }^{\circledR}$ pressure transducers. Image represents 172 planned pressure taps including nine $40 \mathrm{kHz}$ pressure transducers. The final count was 167 taps with seven $40 \mathrm{kHz}$ pressure transducers. 


\section{SRP FLOW STRUCTURE MODES}

The purpose of this paper is to explore the different modes that exist for SRP when varying Mach number, the number of jets, the levels of thrust, and the angle of orientation, and how well CFD can match those modes in behavior and in average surface pressure. SRP literature shows that different modes exist for the 1-nozzle configuration depending on the jet-tofreestream pressure ratio [7], [36]. At low ratios, a long-jet penetration mode exists where the jet exhaust is unsteady, similar to a candle flame, and the bow shock has a large and fluctuating standoff distance from the model. At higher ratios, the short-penetration mode exists (described in Section 2) where the flow is much steadier and the bow shock has a smaller standoff distance than the long-jet penetration mode. It was observed in the LRC UPWT test that once in the shortpenetration mode, unsteadiness in the triple point can vary between a periodic oscillation and a smaller scale aperiodic fluctuation. Also, as angle of attack increases, the windward triple point oscillations become larger as the leeward triple point oscillations decrease, then for $\alpha=20^{\circ}$ the steadiness of the shock structure was lost as the barrel plume and bow shock fluctuated chaotically. The CFD solvers did well simulating the 1-nozzle cases of the LRC UPWT test in behavior and in matching the average surface pressure, with a trend that DPLR predicted a steadier flowfield than was seen in the test, and FUN3D and OVERFLOW well predicted the unsteady behavior seen in the test. The different levels of predicted unsteadiness in the codes is attributed to turbulence modeling and grid resolution [15], [16].

More observations from the LRC UPWT test showed that for the 3-nozzle configuration at lower thrust coefficients $(\leq 3)$, the jet-to-jet interactions and bow shock behavior were aperiodically unsteady. The CFD did well in qualitative comparisons of the shock structure behavior, and varying success was obtained when comparing to the average surface pressure. Discrepancies between the codes and test data at the model nose and shoulder implied a difference in how the codes were simulating the jet-to-jet interaction and the unsteady bow shock shedding and how those impacted the model face. A large discrepancy in data acquisition rates did exist between the CFD and wind tunnel test (WTT). Rates were on the order of $10 \mathrm{~Hz}$ for the WTT and $10 \mathrm{kHz}$ for the CFD simulations. An entire CFD run could fit within the time between two pressure tap readings, meaning high frequency fluctuations captured by the CFD codes were not captured by the WTT system, and the low frequency fluctuations captured by the WTT system were not captured by the CFD. This introduced an error source that increased when unsteady frequencies became very high or very low. A few solitary runs at zero angles of attack and $C_{T}$ up to six showed that the bow shock became nearly steady as jet-to-jet interactions decreased due to distinctly defined barrel plumes. The more steady flowfield was desirable for vehicle stability, and this helped build the case for the ARC UPWT test where higher thrust was possible. As explained in reference [17], at higher thrust for the 3-nozzle configuration $(\geq 6)$ at zero angles of attack the flow was much steadier and the CFD compared better qualitatively and quantitatively than for the lower thrust cases from the LRC UPWT test.

For the 4-nozzle configuration, the LRC UPWT test showed a short-penetration bow shock behavior at zero angle of attack. A discrepancy between the CFD codes for this behavior was noted. Runs 307 and 311 were the same in Mach number (4.6) and thrust coefficient (2), but differed in a roll angle of $0^{\circ}$ and $180^{\circ}$, respectively. The test showed the same short-penetration shock behavior for both runs, but DPLR showed a larger standoff distance for run 307, and OVERFLOW showed a larger and fluctuating standoff distance for run 311 . This implied a difference in modes for the 4-nozzle configuration, and the boundary between the modes was not well defined by the CFD codes. As discussed in [17], at higher thrust coefficients, the 4-nozzle configuration did demonstrate a large and fluctuating bow shock standoff distance, and became chaotically unsteady. In the LRC UPWT test, it was shown that for a roll angle of $0^{\circ}$, unsteadiness increased with angle of attack. For a roll angle of $180^{\circ}$, angle of attack $12^{\circ}$ was unsteady while angle of attack $20^{\circ}$ settled into a steadier mode. All these behaviors were simulated well with the CFD solvers with the exception at angle of attack $0^{\circ}$ already discussed. The average surface pressures for the LRC UPWT test compared well between the codes for all cases, with the largest discrepancies found at the model shoulder. Similar to the 3-nozzle configuration, the differences in average $C_{P}$ at the shoulder implies differences in simulated bow shock shedding that impacts the model face.

\section{RESUltS}

The CFD run matrix (Table 1) consisted of 31 cases varying in Mach number, nozzle configuration, thrust coefficient $\left(C_{T}\right)$, and angles of orientation. All runs in the CFD matrix had a Reynolds number per foot of 1.5 million with the exception of run 223, which had 1.0 million. For the angles of orientation, most cases vary only in $\beta$ angle since the $\beta$ plane provided better shadowgraph imagery for qualitative comparisons. Runs 279 and 309 included non-zero $\alpha$ angles and were meant to compare total alpha angles $\left(\alpha_{T}\right)$ of $12^{\circ}$ at different roll angles $(\phi)$. Each nozzle configuration will now be discussed in more detail. The 0-nozzle configuration will be skipped since it was already covered in reference [17]. Also discussed in reference [17] are the effects of the sting on pressure measurements from the test. The sting caused an increase in the average $C_{P}$ over the aft $30 \%$ of the model. None of the CFD simulations in this paper include the sting, so will underpredict the average $C_{P}$ in that region.

All cases in the run matrix were computed with OVERFLOW, while a smaller subset was computed with FUN3D and DPLR. For the flowfield images, unless otherwise labeled, the CFD solver is OVERFLOW. The line plots in this section compare the average surface pressure from the CFD results and the WTT data along $\theta=0^{\circ}$ and $180^{\circ}$ (see Figure 3). 
Table 1. CFD Run Matrix

\begin{tabular}{|c|c|c|c|c|c|c|}
\hline Run & Mach & Jets & $C_{T}$ & $\alpha$ & $\bar{\beta}$ & $\phi$ \\
\hline 106 & 1.8 & 1 & 4 & $0^{\circ}$ & $0^{\circ}$ & $180^{\circ}$ \\
\hline 116 & 2.4 & 1 & 4 & $0^{\circ}$ & $0^{\circ}$ & $180^{\circ}$ \\
\hline 223 & 2.4 & 1 & 4 & $0^{\circ}$ & $0^{\circ}$ & $0^{\circ}$ \\
\hline 223 & 2.4 & 1 & 4 & $0^{\circ}$ & $-4^{\circ}$ & $0^{\circ}$ \\
\hline 223 & 2.4 & 1 & 4 & $0^{\circ}$ & $-8^{\circ}$ & $0^{\circ}$ \\
\hline 223 & 2.4 & 1 & 4 & $0^{\circ}$ & $-12^{\circ}$ & $0^{\circ}$ \\
\hline 101 & 1.8 & 1 & 2 & $0^{\circ}$ & $0^{\circ}$ & $180^{\circ}$ \\
\hline 104 & 1.8 & 1 & 3 & $0^{\circ}$ & $0^{\circ}$ & $180^{\circ}$ \\
\hline 112 & 2.4 & 1 & 2 & $0^{\circ}$ & $0^{\circ}$ & $180^{\circ}$ \\
\hline 130 & 1.8 & 3 & 6 & $0^{\circ}$ & $0^{\circ}$ & $180^{\circ}$ \\
\hline 132 & 1.8 & 3 & 8 & $0^{\circ}$ & $0^{\circ}$ & $180^{\circ}$ \\
\hline 139 & 2.4 & 3 & 4 & $0^{\circ}$ & $0^{\circ}$ & $180^{\circ}$ \\
\hline 139 & 2.4 & 3 & 4 & $0^{\circ}$ & $12^{\circ}$ & $180^{\circ}$ \\
\hline 141 & 2.4 & 3 & 6 & $0^{\circ}$ & $0^{\circ}$ & $180^{\circ}$ \\
\hline 141 & 2.4 & 3 & 6 & $0^{\circ}$ & $4^{\circ}$ & $180^{\circ}$ \\
\hline 141 & 2.4 & 3 & 6 & $0^{\circ}$ & $8^{\circ}$ & $180^{\circ}$ \\
\hline 141 & 2.4 & 3 & 6 & $0^{\circ}$ & $12^{\circ}$ & $180^{\circ}$ \\
\hline 143 & 2.4 & 3 & 8 & $0^{\circ}$ & $0^{\circ}$ & $180^{\circ}$ \\
\hline 126 & 1.8 & 3 & 2 & $0^{\circ}$ & $0^{\circ}$ & $180^{\circ}$ \\
\hline 145 & 2.4 & 3 & 10 & $0^{\circ}$ & $0^{\circ}$ & $180^{\circ}$ \\
\hline 279 & 2.4 & 3 & 6 & $6^{\circ}$ & $-10.33^{\circ}$ & $30^{\circ}$ \\
\hline 309 & 2.4 & 3 & 6 & $-6^{\circ}$ & $10.33^{\circ}$ & $210^{\circ}$ \\
\hline 166 & 1.8 & 4 & 2 & $0^{\circ}$ & $0^{\circ}$ & $0^{\circ}$ \\
\hline 170 & 1.8 & 4 & 6 & $0^{\circ}$ & $0^{\circ}$ & $0^{\circ}$ \\
\hline 172 & 1.8 & 4 & 8 & $0^{\circ}$ & $0^{\circ}$ & $0^{\circ}$ \\
\hline 179 & 2.4 & 4 & 4 & $0^{\circ}$ & $0^{\circ}$ & $0^{\circ}$ \\
\hline 179 & 2.4 & 4 & 4 & $0^{\circ}$ & $-4^{\circ}$ & $0^{\circ}$ \\
\hline 179 & 2.4 & 4 & 4 & $0^{\circ}$ & $-8^{\circ}$ & $0^{\circ}$ \\
\hline 181 & 2.4 & 4 & 6 & $0^{\circ}$ & $0^{\circ}$ & $0^{\circ}$ \\
\hline 183 & 2.4 & 4 & 8 & $0^{\circ}$ & $0^{\circ}$ & $0^{\circ}$ \\
\hline 185 & 2.4 & 4 & 10 & $0^{\circ}$ & $0^{\circ}$ & $0^{\circ}$ \\
\hline
\end{tabular}

\section{1-Nozzle Configuration}

The highest $C_{T}$ for the 1-nozzle configuration in the ARC UPWT test was 4 . The limiting factor was the high pressure system used for the jet exhaust. The CFD matrix focused on $C_{T}$ of 4 with runs 106,116 , and 223 , and how the behavior at that $C_{T}$ varied with Mach number and $\beta$ angle. Runs 101, 104, and 112 looked into lower thrust coefficients. All cases demonstrated the short-penetration mode described in Section 2.

Figure 4 visualizes the effect of $C_{T}$ as seen in the test and how well the CFD matched that behavior. The increased size of the barrel plume was simulated well with OVERFLOW, and average surface pressures matched well, but consistently underpredicted in the aft region of the model due to not modeling the sting. For run 104, the average $C_{P}$ was overpredicted on the model face, caused by OVERFLOW predicting a periodic oscillation of the triple point. Shedding from the triple point propagates to the model face, which in turn affects the $C_{P}$ on the surface. When the shedding is periodic instead of random, the energy is more organized and the average $C_{P}$ increases. Periodic shedding was not seen in the test for this run.

The effects of increasing $\beta$ angle is shown in Figure 5. As $\beta$ angle increased, the windward triple point oscillation became more pronounced as the leeward triple point became more stationary. This was predicted well by OVERFLOW, and the average surface $C_{P}$ compared well on the model face with some underprediction on the model side. Run $223 \beta=12^{\circ}$ from the ARC UPWT test was similar in triple point behavior as run $165 \alpha=12^{\circ}$ from the LRC UPWT test [15], [16].
Figure 6 combines the results from all codes and the test for run 223, $\beta=0^{\circ}$. The DPLR simulation reached a steady state where FUN3D predicted a periodic oscillation of the triple point, and OVERFLOW predicted the more random triple point oscillation as seen in the test. On the model face, all codes overpredicted the average $C_{P}$ near the shoulder, with FUN3D overpredicting the most due to simulating an organized shedding from the triple point. Along the model side, no significant differences were noted between the codes, and all underpredicted towards the aft end of the model due to not including the sting in the simulations. 

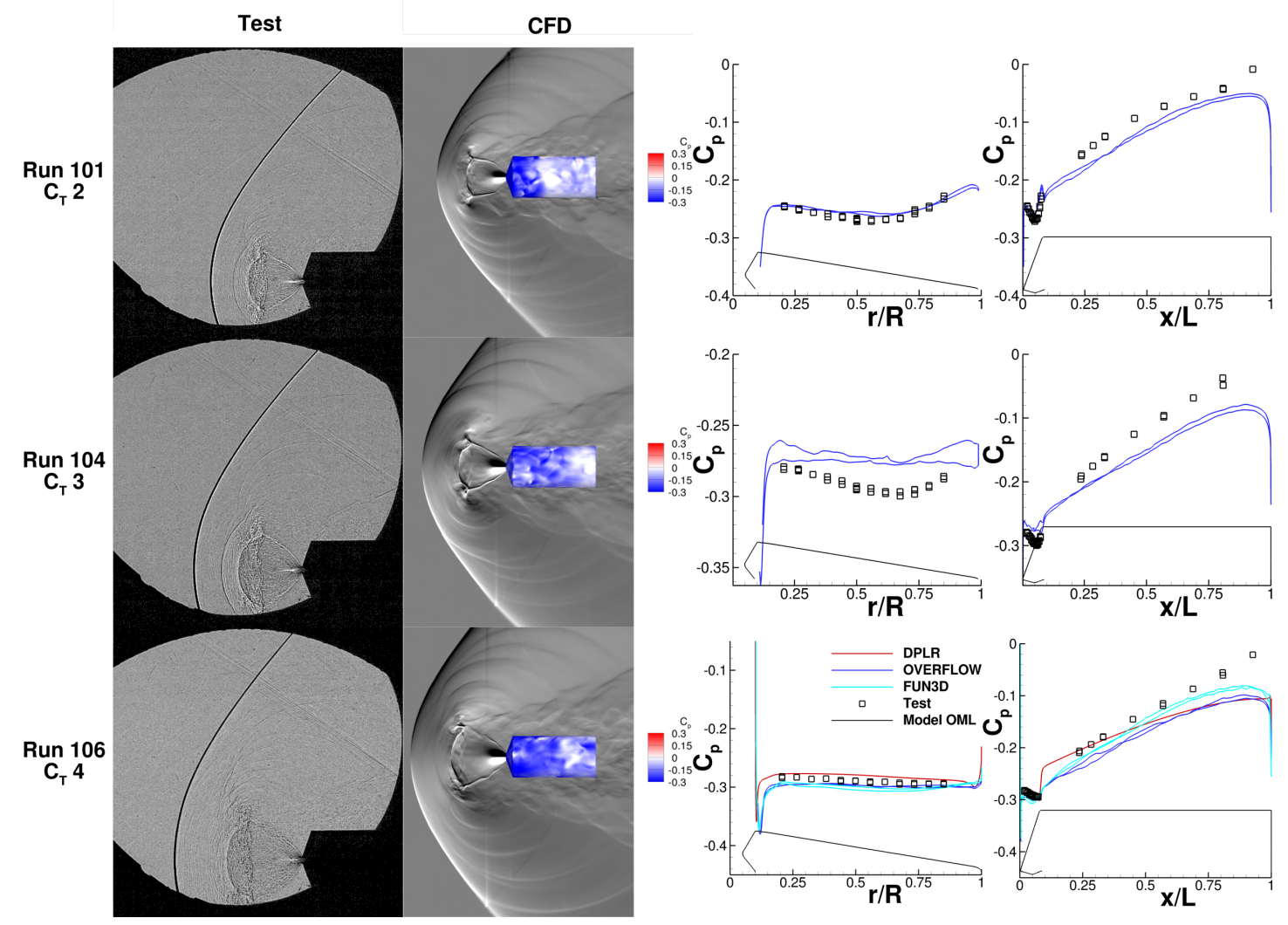

Figure 4. Effects of $C_{T}$; test shadowgraph compared to CFD constructed Schlieren and average surface pressure comparison for the 1-nozzle configuration at Mach 1.8.

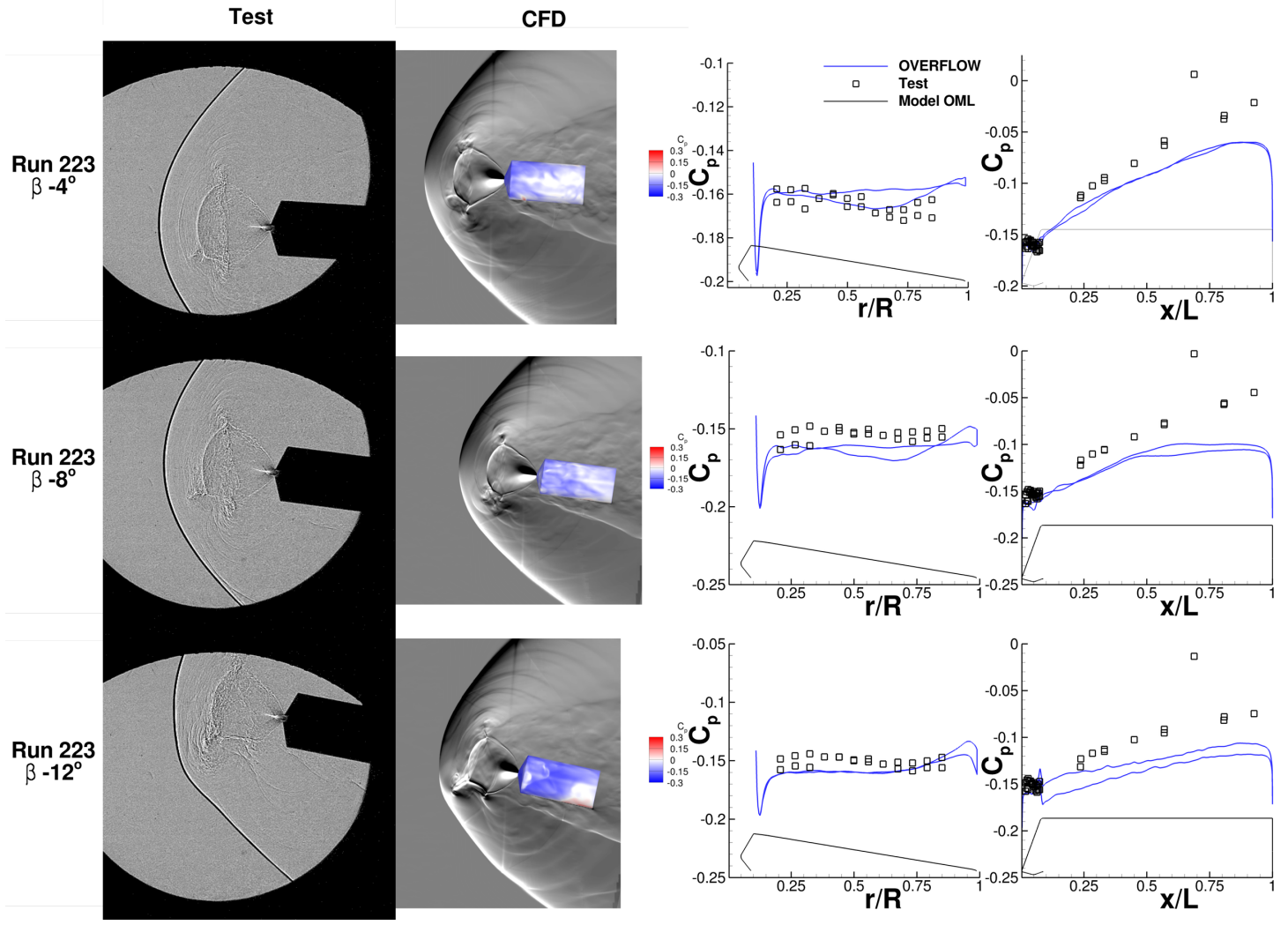

Figure 5. Effects of $\beta$; test shadowgraph compared to CFD constructed Schlieren and average surface pressure comparison for the 1-nozzle configuration, run 223: Mach 2.4, $C_{T} 4$. 


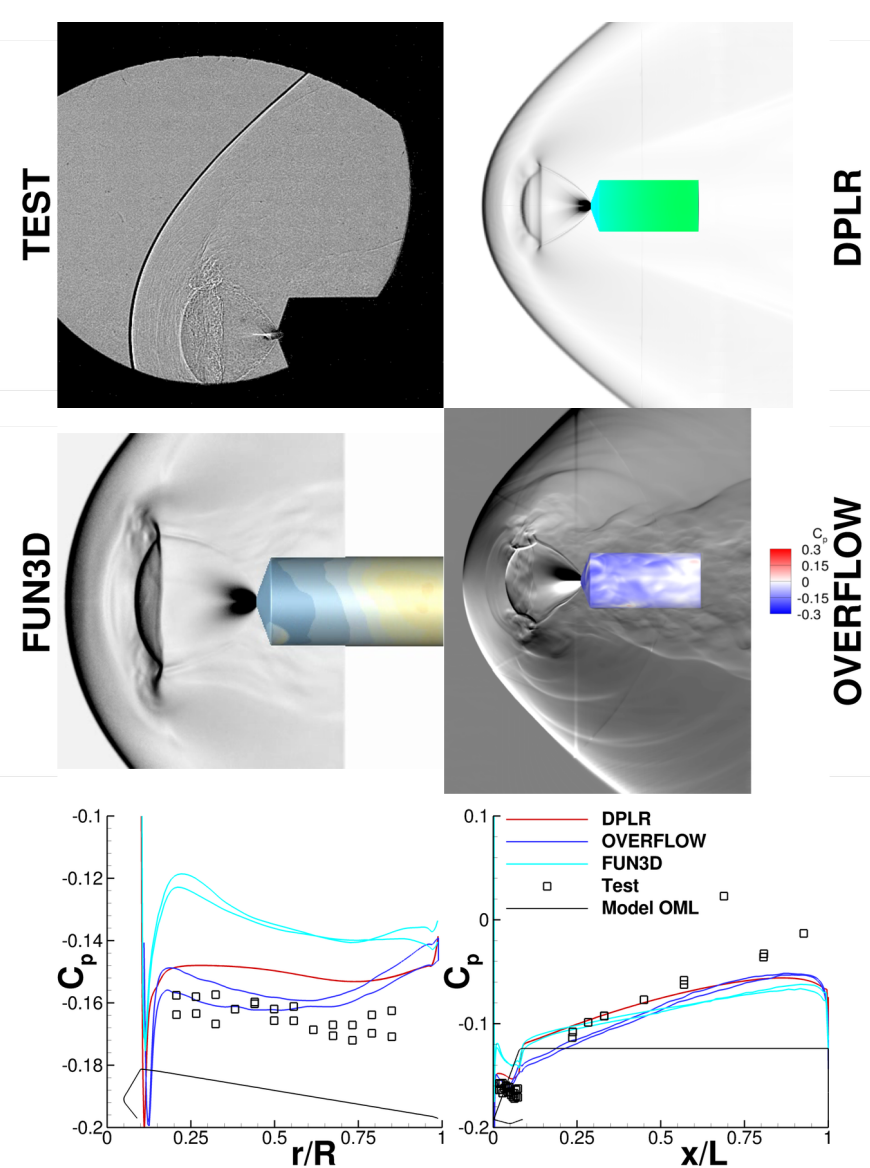

Figure 6. Code-to-code and code-to-test comparison of Run 223: 1-nozzle, Mach 2.4, $C_{T} 4, \beta 0^{\circ}$.

Given the close comparisons in behavior and in average surface $C_{P}$, CFD fairs well for simulating the 1-nozzle configuration. Some differences existed in the level of unsteadiness predicted by the solvers, which did not significantly affect differences in the average $C_{P}$. Two traits of the CFD that did affect the comparison to the tunnel data were sting effects and incorrectly predicting the triple point behavior.

\section{3-Nozzle Configuration}

As discussed in section 5, the higher thrust coefficients tested in the ARC UPWT demonstrated steadier flow than the lower thrust coefficients seen in the LRC UPWT test. This same trend is also shown in Figure 7 where run 126 was more unsteady at a $C_{T}$ of 2 than runs 130 and 132 which were at $C_{T}$ s of 6 and 8, respectively. The OVERFLOW results for run 126 differed in behavior and in average surface $C_{P}$ from the test, especially at the model nose. As $C_{T}$ increased, the steadiness did as well, as did the agreement with the CFD simulations. Good agreement was seen between the codes, with the largest differences at the model nose and near the nozzle. The CFD underpredicted the $C_{P}$ for the majority of the model face and side, with overpredictions at the nose by FUN3D for run 130 and by OVERFLOW for run 132 . OVERFLOW closely matched the test average $C_{P}$ at the nose for run 130, and near the nozzle for runs 130 and 132. DPLR, which reached a steady state solution, closely matched the average $C_{P}$ on the model side for run 130 .

As $\beta$ increased (see Figure 8) the test showed the shock structure maintaining its basic shape, with a noticeable difference in the windward triple point of the windward plume which increased in oscillation size. This same behavior existed for all tested $\beta$ angles up to $12^{\circ}$. Here lies a weakness in the OVERFLOW results. For $\beta$ angles up to $8^{\circ}$, the windward plume maintained its shape, but for $\beta=12^{\circ}$, the windward plume was compressed, and the resulting flow structure was more unsteady than what was seen in the test. The difference in flow behavior did not greatly influence the average surface pressure comparison, all cases still compared well to the test data.

The effects of roll $(\phi)$ at high angle of attack is shown in Figure 9. In the test, the three barrel plumes still maintained their shapes regardless of roll, but in the OVERFLOW results, only $\phi=210^{\circ}$ showed that behavior where the rest showed the compressed windward plume. For the cases with $\phi=180^{\circ}$ and $30^{\circ}$, the compressed plume was more directly in line with the oncoming tunnel flow, or more relatively windward than for the $\phi=210^{\circ}$ case. For the $\phi=210^{\circ}$ case, the two windward plumes were equally windward, and neither were as directly in-lined with the flow as the other $\phi$ cases.

The high pressure at the nose of the model for the 3-nozzle configurations should not be taken to be resultant of oncoming freestream flow penetrating the space between the plumes. Instead, the high pressure region is caused by a recirculation zone created by entrapment of jet exhaust and entrainment from surrounding flow. Differences in surface $C_{P}$ between the codes can be attributed to differences in modeling the recirculation caused by that entrainment and entrapment. 


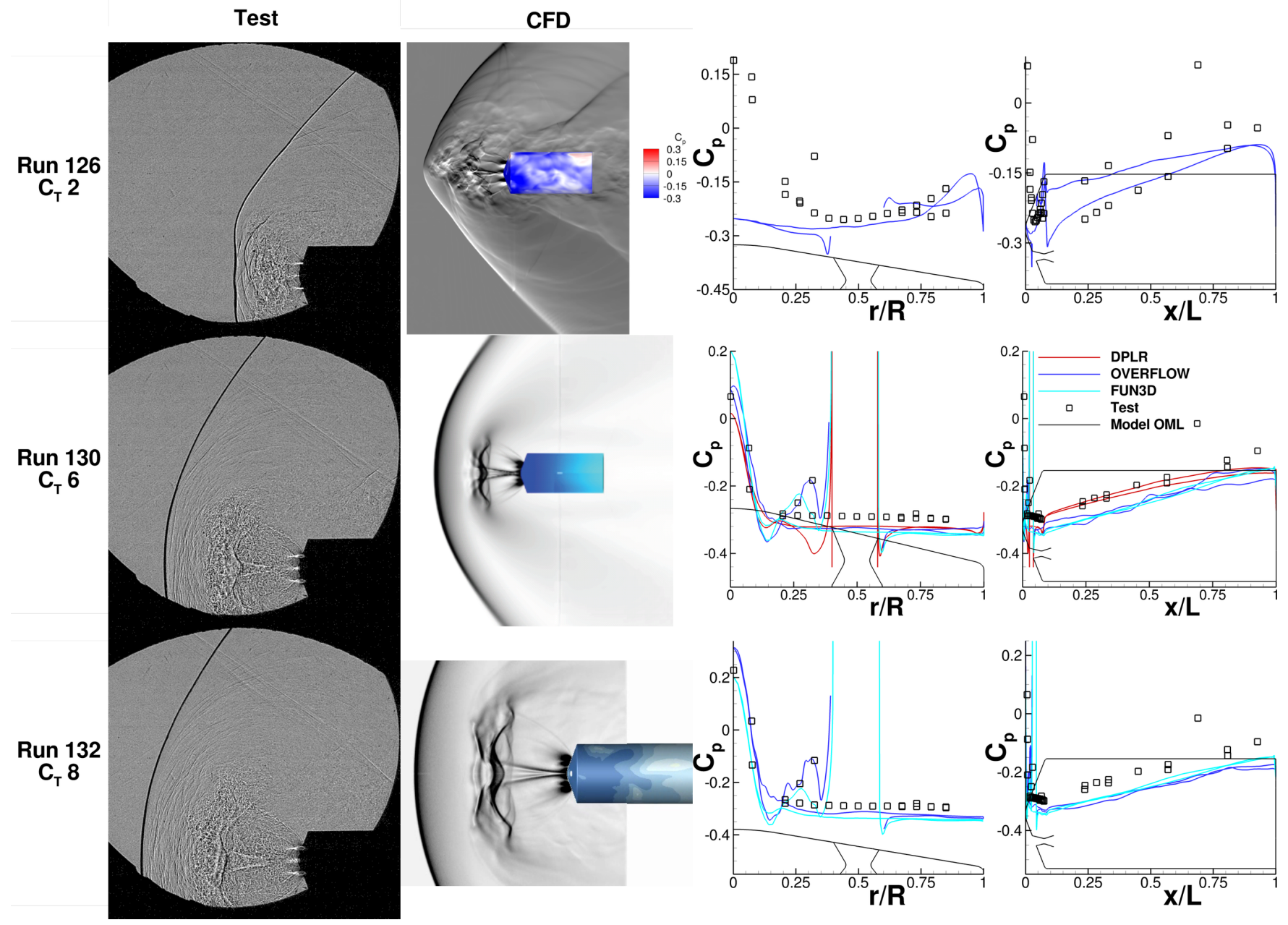

Figure 7. Effects of $C_{T}$; test shadowgraph compared to CFD constructed Schlieren/shadowgraph and average surface pressure comparison for the 3-nozzle configuration at Mach 1.8. The CFD solver visualizations for runs 126, 130, and 132 are OVERFLOW, DPLR, and FUN3D, respectively. 


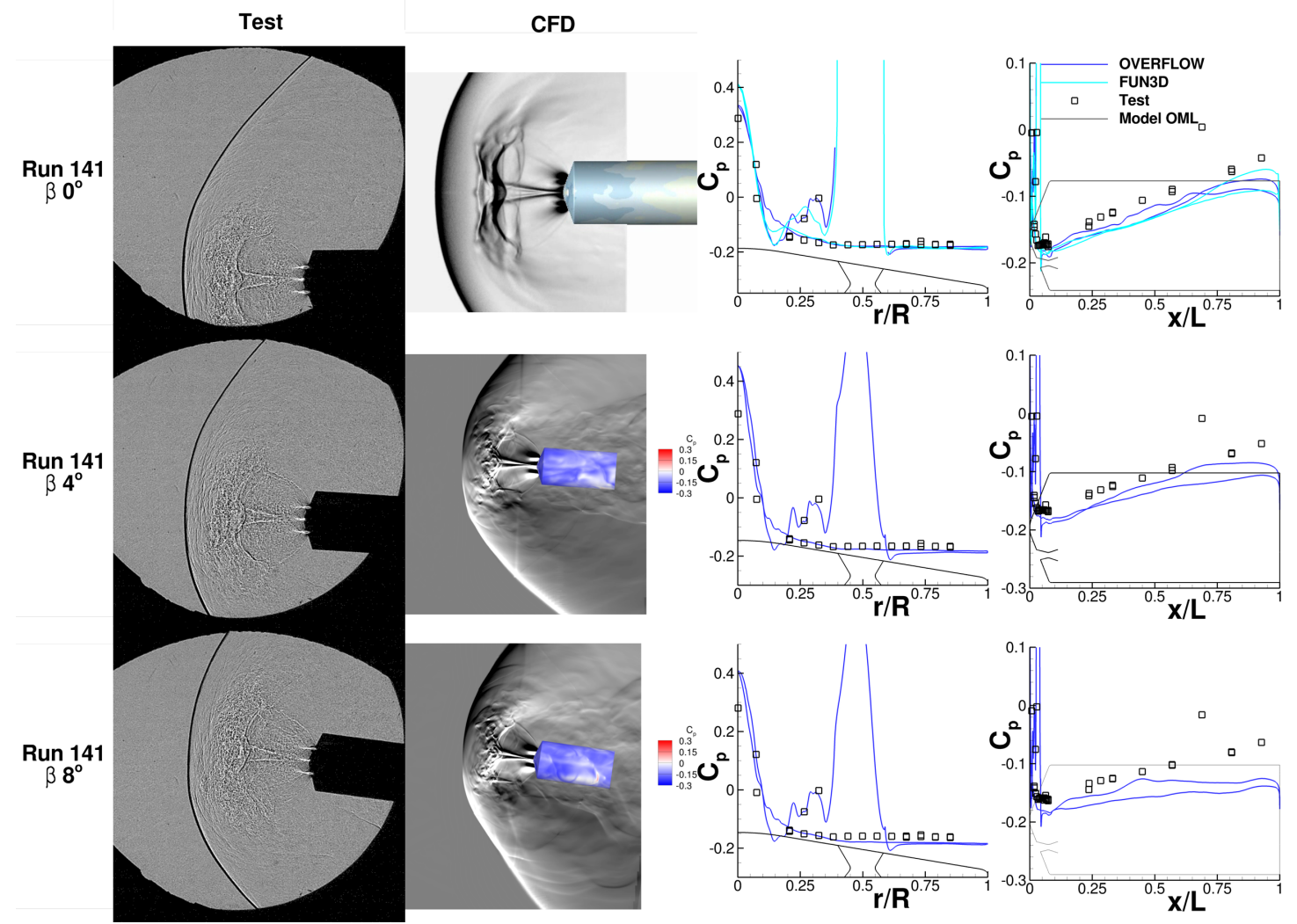

Figure 8. Effects of $\beta$; test shadowgraph compared to CFD constructed Schlieren/shadowgraph and average surface pressure comparison for the 3-nozzle configuration, run 141: Mach 2.4, $C_{T}$ 6. The CFD solver visualization for $\beta=0^{\circ}$ is FUN3D, and for the other $\beta$ angles is OVERFLOW.

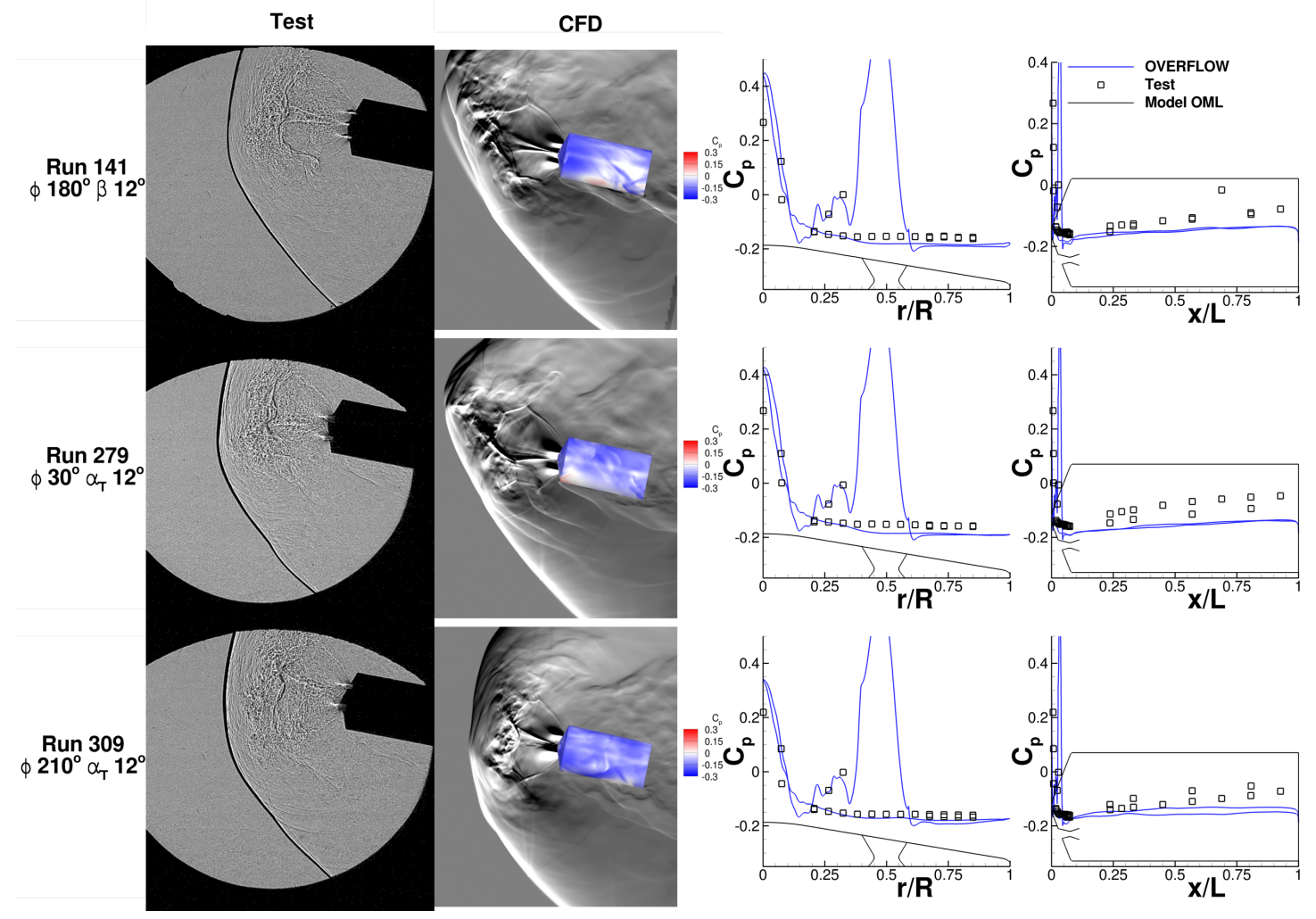

Figure 9. Effects of $\phi$; test shadowgraph compared to CFD constructed Schlieren and average surface pressure comparison for the 3-nozzle configuration at Mach 2.4, $C_{T} 6$. 
Run 139 was used for a code-to-code comparison and is visualized in Figure 10. In the test, the flow was more unsteady than shown in the CFD solvers. FUN3D was closest to the unsteady behavior, but eventually reached a steady state. This demonstrated that the boundaries between different modes of behavior for SRP, in this case the boundary between unsteady and much steadier flow as $C_{T}$ increases, was not captured well by the CFD codes. For the average $C_{P}$, FUN3D overpredicted at the nose and bounded the test data on the model side, DPLR closely matched on the face and side with an underprediction near the nozzle, and OVERFLOW closely matched on the face but predicted nearly symmetric $C_{P}$ on the side.

Confidence in the ability of CFD to simulate 3-nozzle SRP configurations is stronger for higher $C_{T} \mathrm{~s}$ than for lower $C_{T} \mathrm{~s}$. The boundary between the unsteady lower $C_{T} \mathrm{~s}$ and the much steadier higher $C_{T} \mathrm{~s}$ is not well predicted by CFD, but once the steadier mode is obtained, better agreement between the CFD solvers and the test data is achieved. The LRC UPWT CFD validation exercise showed that all solvers closely matched the wind tunnel test qualitatively in behavior, but differences in average surface $C_{P}$ did exist. A possible error source for the CFD may be the grid system, which was optimized for 1-nozzle SRP flow, but may not be optimized

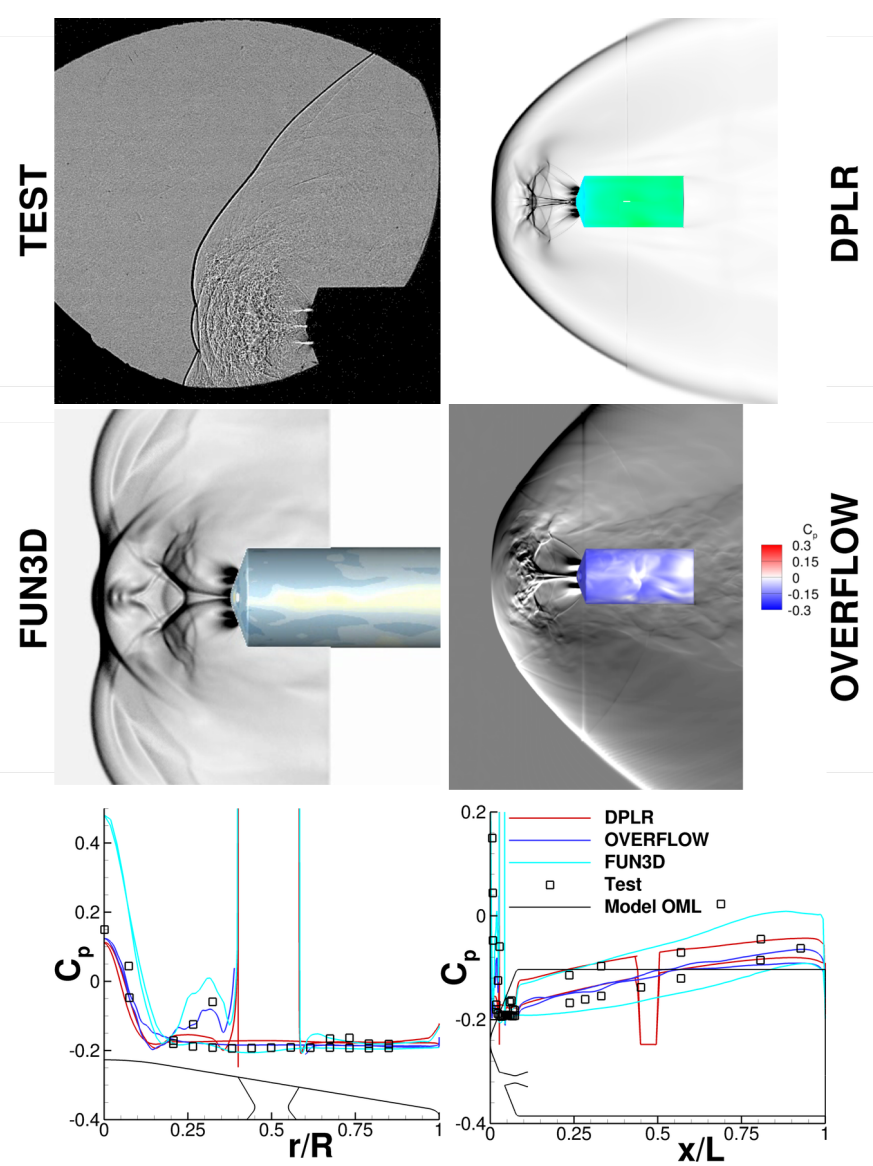

Figure 10. Code-to-code and code-to-test comparison of Run 139: 3-nozzle, Mach 2.4, $C_{T} 4$.

for multi-nozzle flows with interacting shear layers.

\section{4-Nozzle Configuration}

Section 5 discussed that differences in the shock standoff distance as well as the level of unsteadiness changed based on thrust coefficient for zero angle of attack 4-nozzle cases. At lower $C_{T} \mathrm{~s}$ the flow was steadier with a short bow shock standoff distance, and at higher $C_{T}$ s the flow became chaotic with large and oscillating shock standoff distances. This trend was noted in the ARC UPWT test results, which ranged from a $C_{T}$ of 2 for run 166 to a $C_{T}$ of 10 for run 185 of the CFD matrix. The CFD matched the behavior of the zero $\beta$ cases well, but not much value was placed in the average surface pressure comparisons. Since the flow was chaotic and the data acquisition rates varied so greatly between the CFD and WTT data, the averages obtained by the CFD and WTT differed greatly. The WTT data acquisition rates were also not sufficient to gather enough samples for this chaotic flow.

As $\beta$ angle increased, the level of unsteadiness decreased in the test, as seen with run 179 in Figure 11. This behavior was not matched by OVERFLOW, which continued to predict a highly chaotic flowfield at $\beta$ angles of $4^{\circ}$ and $8^{\circ}$. This may be a limitation in the grid system, which was optimized for a 1-nozzle configuration and then applied to multi-nozzle configurations. 


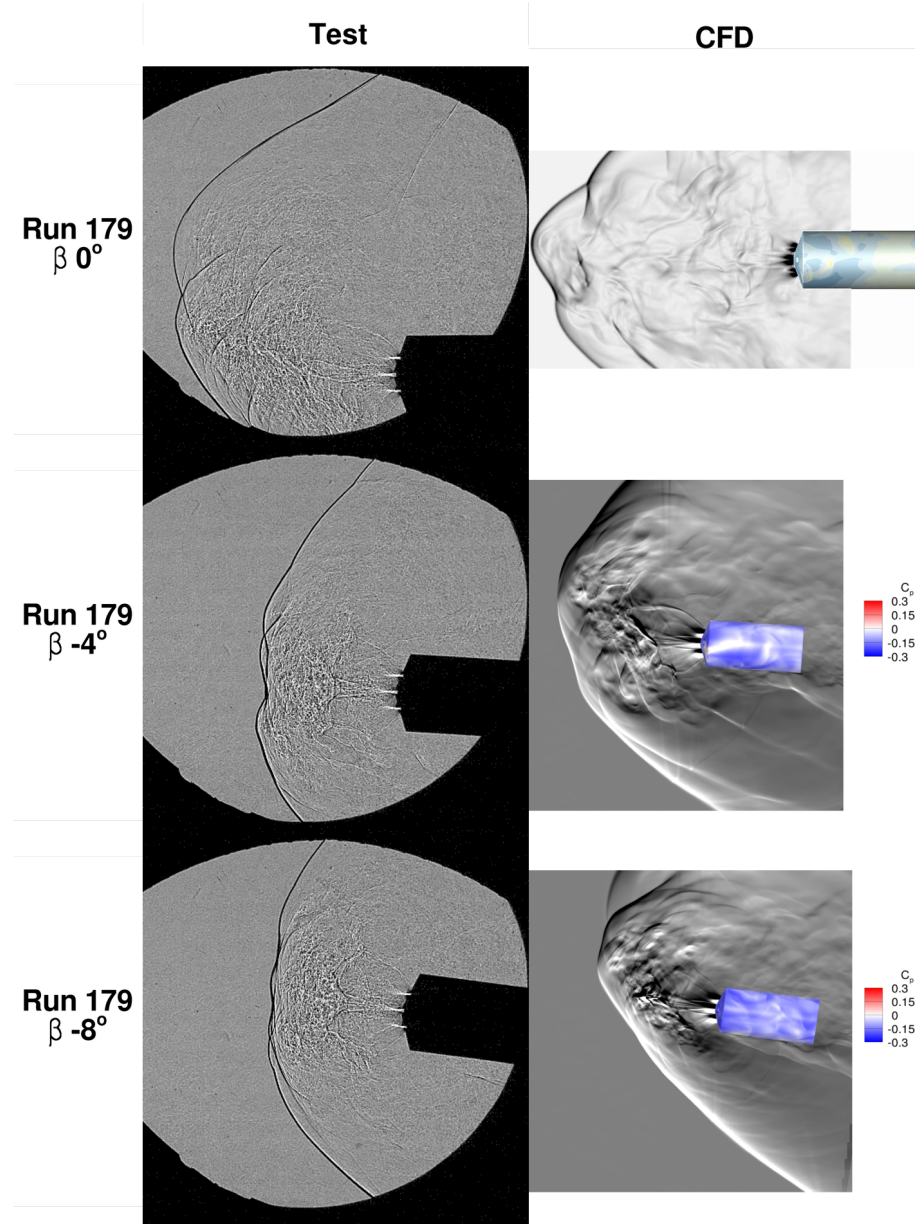

Figure 11. Effects of $\beta$; test shadowgraph compared to CFD constructed Schlieren/shadowgraph and average surface pressure comparison for the 4-nozzle configuration, run 179: Mach 2.4, $C_{T}$ 4. The CFD solver visualization for $\beta=0^{\circ}$ is FUN3D, and for the other $\beta$ angles is OVERFLOW.

Code-to-code comparisons can be seen in Figure 12 for run 166 (Mach 1.8, $C_{T}$ 4). The test still demonstrated the steadier, short shock standoff distance of lower thrust coefficients. This behavior was matched by FUN3D and OVERFLOW, but a large standoff distance was predicted by DPLR. The average surface $C_{P}$ by DPLR overpredicted FUN3D and OVERFLOW, both of which were closer to the test data. The FUN3D $C_{P}$ data showed a more dynamic behavior than OVERFLOW and DPLR, a result of insufficient averaging.

The confidence in the ability of the CFD solvers to simulate 4-nozzle flow is not as strong as it is for the 1-nozzle configuration. The change in the short-penetration standoff distance to the wildly chaotic behavior was predicted to be at different points between the CFD solvers. Due to the highly unsteady behavior of the 4-nozzle configuration at $C_{T} \mathrm{~s}$ greater than four, it was difficult to obtain reasonable average surface pressure comparisons between the CFD and the WTT. Also, steadier modes at angle of attack were seen for the 4-nozzle configuration which were not simulated with the CFD.

\section{Thrust Dominance}

For the SRP cases discussed, the total axial force $\left(C_{A, t o t a l}=\right.$ $C_{T}+C_{A, \text { aero }}$ ) was dominated by the thrust coefficient and the contribution of the aerodynamic axial force was very

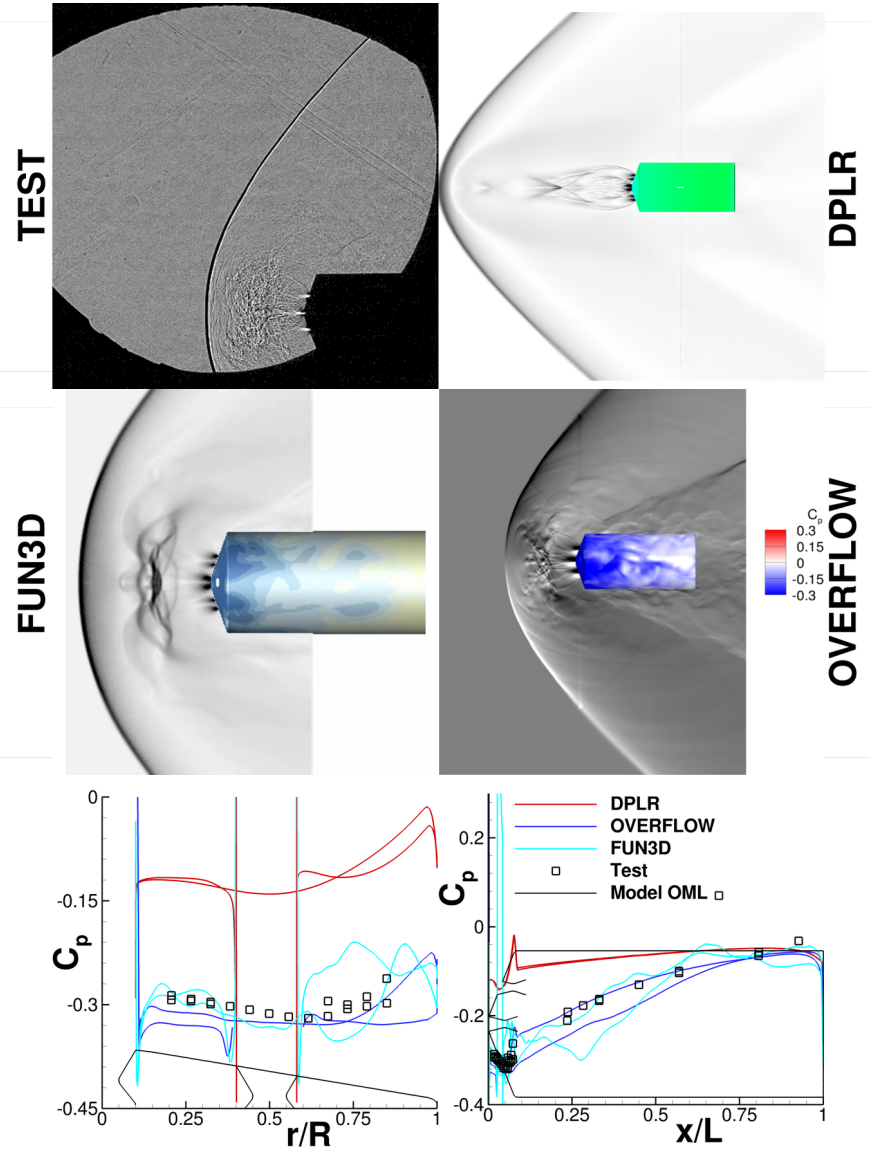

Figure 12. Code-to-code and code-to-test comparison of Run 166: 4-nozzle, Mach 1.8, $C_{T} 4$.

small. This can be seen in the bar chart in Figure 13 where the gray section of the bars represent $C_{T}$ and the blue sections represent $C_{A, \text { aero. }}$. This raises the question to whether aerodynamic effects are negligible for these types of SRP flows. More research needs to be conducted to answer this question. Entry trajectories and angles as well as spacecraft scale need to be taken into consideration. A high frequency oscillation at the WTT scale will be a much lower frequency at the flight scale, and may have more contribution to vehicle stability. Normal force and the vehicle moments also need to be taken into consideration, especially for non-zero vehicle entry angles.

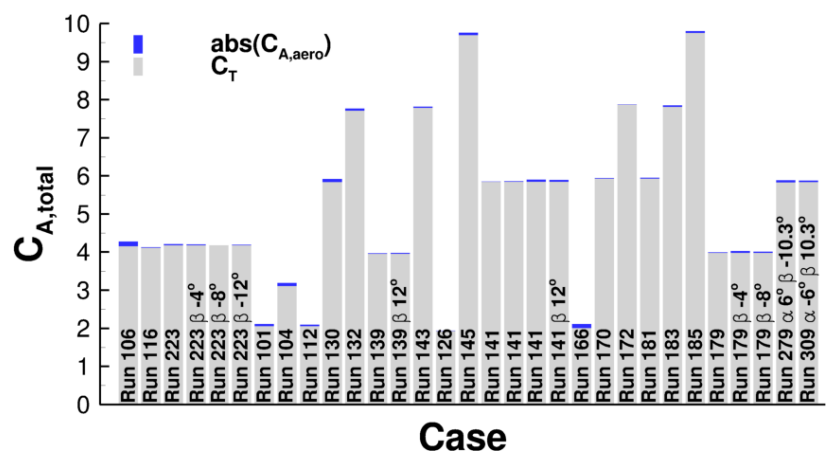

Figure 13. Comparison of the contributions of thrust and aerodynamics to the total axial force for the ARC UPWT CFD cases run by OVERFLOW. 


\section{Computational Cost}

Table 2 shows a breakdown of the computational cost for each of the codes for a typical SRP run. This is not a perfect comparison since the numbers represented are either just from a single run or averages of multiple runs. All cases were computed on the Pleiades NASA Advanced Supercomputing cluster, an SGI Ice cluster, on either Nehalem or Westmere nodes. Since each code used different amounts of time, number of iterations, number of sub-iterations, and number of grid points, a common metric of CPU seconds per iteration per grid point between the codes is reported for comparison.

Part of the requirement for these validation runs was to test the ability of the solvers to predict the SRP flowfields. For this reason, time-accurate runs were necessary because it is impossible to know beforehand if the unsteady effects played a large role in the aerodynamic effects. Costs for validation cases were large; however, for production runs of parametric studies or database generation, the computational costs should be able to drop significantly as either steady state runs or higher efficient numerical and time step processes are adopted.

Table 2. Computational Cost Per Case

\begin{tabular}{lllll}
\hline Solver & CPU & Iterations & $\begin{array}{l}\text { Grid } \\
\text { Points }\end{array}$ & $\begin{array}{l}\text { CPU } \\
\text { s/iter/gp }\end{array}$ \\
\hline FUN3D & 28,000 & 39,500 & $4.2 \mathrm{e} 7$ & $6.1 \mathrm{e}-05$ \\
DPLR & 44,500 & 106,000 & $5.3 \mathrm{e} 7$ & $2.9 \mathrm{e}-05$ \\
OVERFLOW & 35,039 & 73,500 & $8.5 \mathrm{e} 7$ & $2.0 \mathrm{e}-05$ \\
\hline
\end{tabular}

\section{Conclusions}

A second wind tunnel test for validation of CFD in SRP conditions was conducted in the ARC UPWT $9^{\prime} \times 7^{\prime}$ tunnel. The ARC UPWT test had a larger test section than the previous test, which took place in the LRC UPWT $4^{\prime} \times 4^{\prime}$ tunnel. With the larger test section, higher thrust coefficients were obtained that closer match flight requirements.

For the 1-nozzle configuration, not much difference was observed between the higher thrust coefficients of 4 obtained in the ARC UPWT and the lower thrust coefficients of 2 obtained in the LRC UPWT. The short-penetration shock interaction structure was observed, and oscillations at the triple point increased for the windward triple point as angle of attack was increased. The CFD solvers compared well to the 1-nozzle cases in the CFD matrix, only varying in predicting periodic oscillations of the triple point when random oscillations were observed in the test. Average surface pressure comparisons were promising, building confidence in the ability of CFD to predict 1-nozzle configuration SRP.

For the 3-nozzle configuration, the unsteady behavior noted at lower thrust coefficients of 2 did not exist for higher thrust coefficients where the flow structure becomes more steady, especially in the bow shock. This behavior was predicted well with the CFD, and average surface pressures agreed well with the WTT. The area of greatest deviation between the codes was along the model shoulder and at the model nose. The differences at the nose are attributed to differences in entrainment, entrapment, and recirculation being simulated between the codes at the model nose, as well as any shear layer interaction that may be occurring between the plumes. At $\beta$ and $\alpha_{T} 12^{\circ}$, OVERFLOW did not predict the same be- havior as the WTT, predicting a more compressed windward barrel plume for most cases. This discrepancy in qualitative comparison did not seem to greatly influence the average surface pressure comparison.

For the 4-nozzle configuration, a steadier mode with a short shock standoff distance existed for lower $C_{T} \mathrm{~s}$. As $C_{T}$ was increased, the flow becomes highly unsteady with the bow shock standoff distance aperiodically oscillating between small and large standoff distances. The unsteady flowfield was predicted well with the CFD codes, but the average surface pressures were not comparable to WTT data, presumably due to large differences in data acquisition rates between the CFD and WTT and the large difference in time-averaging windows. At $\beta 4^{\circ}$ and $8^{\circ}$, a steadier mode was noted which was not predicted by OVERFLOW, which continued to predict a largely chaotic flowfield.

Given the comparisons in this validation study, confidence was built in the ability of CFD to simulate 1-nozzle configurations at all $\beta$ angles tested, and high thrust 3-nozzle configurations at $\beta \leq 8^{\circ}$. The ability to simulate the behavior seen in the high thrust 4-nozzle cases was also demonstrated, but average surface pressure comparisons were poor. The ability of the CFD codes to predict the exact boundary between steady and unsteady modes for 1-, 3-, and 4-nozzle configurations was not demonstrated, and in fact offered contradictory results in both the LRC UPWT and ARC UPWT tests for the 4-nozzle $\alpha / \beta$ zero configuration. The average surface pressure comparisons were the best for the 1-nozzle configuration and for the steadier runs of the 3 - and 4-nozzle configurations. This correlates to steadier flowfields where the large difference in data acquisition rates between the CFD WTT did not greatly influence the averages obtained. Another possible error source may be the grid systems used for each code which were optimized for 1nozzle SRP flow, not for multi-nozzle flows with shear layer interactions.

Thrust dominance and computational costs were also mentioned. Computational costs were high for validation but could be much less for production.

Future work for CFD validation would include live rocket tests including startup transients, more flight-relevant calculations including Mars atmospheric and rocket nozzle gases, and an application to flight-scaled spacecraft to better understand the influence of aerodynamics on stability and control. Future wind tunnel tests could include pressure measurement instrumentation along the model shoulder to help validate CFD in that area. More CFD research may be needed to properly define the boundaries between different behavioral modes, as well as an optimization of a grid system for multinozzle SRP flowfields.

\section{ACKNOWLEDGMENTS}

Pieter G. Buning of NASA Langley Research Center, Hampton, Virginia; Phillip C. Stuart, Thomas M. Booth, and Darby J. Vicker of NASA Johnson Space Center, Houston, Texas provided valuable guidance on gridding and solver best practices for OVERFLOW. William T. Jones of NASA Langley Research Center, Hampton, Virginia provided the GridEx/batchEx unstructured grid generation framework and helped with its application to generate FUN3D grids. Todd R. White and Andrew J. Hyatt of ERC inc., Moffett Field, California helped develop DPLR best practices and pro- 
vided overset gridding assistance for DPLR cases. David A. Saunders of ERC Inc., Moffett Field, California developed the code used for OVERFLOW and DPLR simulated Schlieren/shadowgraph visualizations.

The authors would like to acknowledge the support of the Exploration Technology Development and Demonstration (ETDD) Program, which was managed at NASA-Glenn Research Center. The work documented herein was performed as part of ETDD's Entry, Descent, and Landing (EDL) Technology Development Project, which was managed at NASALangley Research Center and supported by NASA-Ames Research Center, NASA-Johnson Space Center, and the Jet Propulsion Laboratory.

\section{REFERENCES}

[1] Braun, R. D., and Manning, R. M., "Mars Exploration Entry, Descent, and Landing Challenges," Journal of Spacecraft and Rockets, Vol. 44, No. 2, 2007, pp. 310323.

[2] Steinfeldt, B. A., Theisinger, J. E., Korzun, A. M., Clark, I. G., Grant, M. J., and Braun, R. D., "High Mass Mars Entry, Descent, and Landing Architecture Assessment," AIAA Paper 2009-6684, September 2009.

[3] Zang, T.A., and Munk, M. M., et al., "Entry, Descent and Landing Systems Analysis Study: Phase 1 Report," NASA TM 2010-216720, July 2010.

[4] Edquist, K. T., Dyakonov, A. A., Korzun, A. M., Shidner, J. D., Studak, J. W., Tigges, M. A., Kipp, D. M., Prakash, R., Trumble, K. A., Dupzyk, I. C., "Development of Supersonic Retro-Propulsion for Future Mars Entry, Descent, and Landing Systems," AIAA Paper 2010-5046, June 2010.

[5] Korzun, A. M., and Braun, R. D., "Performance Characterization of Supersonic Retropropulsion for High-Mass Mars Entry Systems,' Journal of Spacecraft and Rockets, Vol. 47, No. 5, 2010, pp. 836-848.

[6] Korzun, A. M., Braun, R. D., and Cruz, J. R., "Survey of Supersonic Retropropulsion Technology for Mars Entry, Descent, and Landing," Journal of Spacecraft and Rockets, Vol. 46, No. 5, 2009, pp. 929-937.

[7] Jarvinen, P. O., and Adams, R. H., "The Aerodynamic Characteristics of Large Angled Cones with Retrorockets," NASA CR NAS 7-576, February 1970.

[8] Trumble, K. A., Schauerhamer, D. G., Kleb, W. L., Carlson, J. R., Buning, P. G., Edquist, K. T., and Barnhardt, M. D., "An Initial Assessment of Navier-Stokes Codes Applied to Supersonic Retro-Propulsion," AIAA Paper 2010-5047, June 2010.

[9] Aeschliman, D. P. and Oberkampf, W. L., "Experimental Methodology for Computational Fluid Dynamics Code Validation," AIAA Journal, Vol. 36, No. 5, 1998, pp. 733741.

[10] Oberkampf, W. L. and T. G. Trucano, "Verification and Validation in Computational Fluid Dynamics." Progress in Aerospace Sciences, Vol. 38, No. 3, 2002, pp. 209272.

[11] Oberkampf, W. L. and Roy, C. J., Verification and Validation in Scientific Computing, Cambridge, UK, Cambridge University Press, 2010.

[12] Trumble, K. A., Schauerhamer, D. G., Kleb, W. L., and Edquist, K. T., "Analysis of Navier-Stokes Codes
Applied to Supersonic Retro-Propulsion Wind Tunnel Test," IEEEAC Paper 1471, March 2011.

[13] Berry, S. A., Laws, C. T., Kleb, W. L., Rhode, M. N., Spells, C., Mccrea, A. C., Trumble, K. A., Schauerhamer, D. G., Oberkampf, W. L., "Supersonic Retro-Propulsion Experimental Design for Computational Fluid Dynamics Model Validation,” IEEEAC Paper 1499, March 2011.

[14] Berry, S. A., Rhode, M. N., Edquist, K. T., and Player, C. J., "Supersonic Retropropulsion Experimental Results from the NASA Langley Unitary Plan Wind Tunnel," AIAA Paper 2011-3489, June 2011.

[15] Kleb, W. L., Carlson, J. R., Buning, P. G., Berry, S. A., Rhode, M. N., Edquist, K. T., Schauerhamer, D. G., Trumble, K. A., Sozer, E., "Toward Supersonic Retropropulsion CFD Validation," AIAA Paper 20113490, June 2011.

[16] Schauerhamer, D. G., Trumble, K. A., Kleb, W. L., Carlson, J. R., Edquist, K. T., "Continuing Validation of Computational Fluid Dynamics For Supersonic Retropropulsion," AIAA Paper 2012-0864, January 2012.

[17] Zarchi, K. A., Schauerhamer, D. G., Kleb, W. L., Carslon, J. R., Edquist, K. T., "Computational Fluid Dynamics Validation and Post-test Analysis of Supersonic Retropropulsion in the Ames 9x7 Unitary Tunnel," AIAA Paper 2012-2705, June 2012.

[18] Rhode, M. N., Oberkampf, W. L., "Estimation of Uncertainties for a Supersonic Retro-Propulsion Model Validation Experiment in a Wind Tunnel," AIAA Paper 2012-2707, June 2012.

[19] Rhode, M. N., and Oberkampf, W. L., "Estimation of Uncertainties for Supersonic Retropropulsion Test 1853 NASA Langley Research Center Unitary Plan Wind Tunnel,"NASA TR-EDL_01_TR_9217, October 2011.

[20] Berry, S. A., Rhode, M. N., Edquist, K. T., "Supersonic Retropropulsion Experimental Results from the NASA Ames 9- x 7-Foot Supersonic Wind Tunnel," AIAA Paper 2012-2704, June 2012.

[21] MacCormack, R. W. and Candler, G. V., "The Solution of the Navier-Stokes Equations Using Gauss-Seidel Line Relaxation," Computers and Fluids, Vol. 17, No. 1, 1989 , pp. $135-150$.

[22] van Leer, B., "Towards the Ultimate Conservative Scheme. V. A Second-Order Sequel to Godunovs Method," Journal of Computational Physics, Vol. 32, 1979, pp. 101-136.

[23] Yee, H. C., "A Class of High-Resolution Explicit and Implicit Shock Capturing Methods," NASA TM 101088, February 1989.

[24] Menter, F. R., "Two-Equation Eddy-Viscosity Turbulence Models for Engineering Applications," AIAA Journal, Vol. 32, No. 8, 1994, pp. 1598-1605.

[25] Edwards, J. R., "A Low-Diffusion Flux-Splitting Scheme for Navier-Stokes Calculation," Computers and Fluids, Vol. 26, No. 6, 1997, pp. 653-659.

[26] van Albada, G. D., van Leer, B., and Roberts, W. W., "A Comparative Study of Computational Methods in Cosmic Gas Dynamics," Astronomy and Astrophysics, Vol. 108, No. 1, 1982, pp. 76.

[27] Vatsa, V. N. and White, J. A., "Calibration of a Unified Flux Limiter for Ares-Class Launch Vehicles from Subsonic to Supersonic Speeds," JANNAF Paper, April 2009. 
[28] Spalart, P. R. and Allmaras, S. R., "A One-Equation Turbulence Model for Aerodynamic Flows," AIAA Paper 92-0439, January 1992.

[29] Vatsa, V. N., Carpenter, M. H., and Lockard, D. P., "Re-evaluation of an Optimized Second Order Backward Difference (BDF20PT) Scheme for Unsteady Flow Applications," AIAA Paper 2010-0122, January 2010.

[30] Tramel, R., Nichols, R., and Buning, P., "Addition of Improved Shock-Capturing Schemes to OVERFLOW 2.1," AIAA Paper 2009-3988, June 2009.

[31] Wilcox, D. C., "Formulation of the $\kappa-\omega$ Turbulence Model Revisited," AIAA Journal, Vol. 46, No. 11, November 2008.

[32] Wright, M. W., White, T., and Mangini, N., "Data Parallel Line Relaxation (DPLR) Code User Manual Acadia Version 4.01.1," NASA/TM-2009-215388, October 2009.

[33] Anderson, W. K. and Bonhaus, D. L., "An Implicit Upwind Algorithm for Computing Turbulent Flows on Unstructured Grids," Computers and Fluids, Vol. 23, No. 1, 1994, pp. 1-21.

[34] Anderson, W. K., Rausch, R. D., and Bonhaus, D. L., "Implicit/Multigrid Algorithms for Incompressible Turbulent Flows on Unstructured Grids," Journal of Computational Physics, Vol. 128, No. 2, 1996, pp. 391-408.

[35] Nichols, R. H., Buning, P. G., “User's Manual for OVERFLOW 2.1," University of Alabama and NASA Langley Research Center, 2008.

[36] Daso, E. O., Pritchett, V. E., Wang, T. S., Ota, D. K., Blankson, I. M., Auslender, A. H., "Dynamics of Shock Dispersion and Interactions in Supersonic Freestreams with Counterflowing Jets," AIAA Journal Vol. 47, No. 6, June 2009.

[37] Codoni, J. R., Berry, S. A., "Analysis of Dynamic Data from Supersonic Retropropulsion Experiments in NASA Langley's Unitary Plan Wind Tunnel," AIAA Paper 2012-2706, June 2012.

\section{BIOGRAPHY}

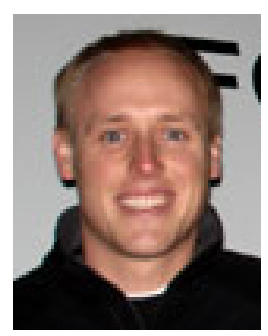

Guy Schauerhamer is an aerospace engineer for Jacobs Technology supporting NASA Johnson Space Center's Applied Aeroscience and CFD Branch. He received his B.S. and M.S. in Mechanical Engineering from Utah State University where his thesis was on six-degree-offreedom moving mesh applications. His primary focus is in the field of computational fluid dynamics, in which he has been involved in the aerodynamic analysis of capsules, Ares V, full aircraft, the Morpheus lander, and Supersonic Retropropulsion.

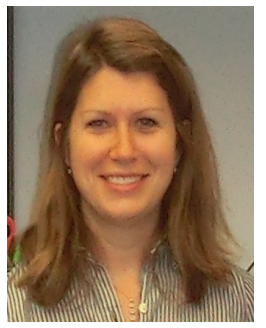

Kerry Zarchi (Trumble) is an aerospace engineer in the Aerothermodynamics Branch at NASA Ames Research Center. Her primary focus is in the field of hypersonic computational fluid dynamics, in which she has been involved in the aerothermal analysis of Stardust, Orion Crew Exploration Vehicle, Space Shuttle Damage Assessment, and Supersonic Retropropulsion. She received her B.S. in Mechanical Engineering from Michigan Technological University and her M.S. in Aerospace Engineering from University of Minnesota, where her thesis was on flow control through laser energy deposition.

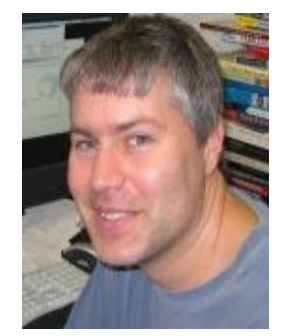

Bil Kleb is an aerospace engineer in the Aerothermodynamics Branch at NASA Langley Research Center. His main area of research has been the development and application of hypersonic computational fluid dynamics codes such as LAURA and FUN3D. He has a long history of providing aerothermodynamic analysis of the shuttle and has contributed to numerous NASA space access studies such as X-33, X-34, X-37, and Orion. His current research focuses on verification and validation of computational fluid dynamic models to enable prediction of Mars decelerator reentry performance. He has a B.S. and M.S. in Aeronautics and Astronautics from Purdue University, an M.B.A. from the College of William and Mary, and a Ph.D. in Aerospace Engineering from the University of Michigan.

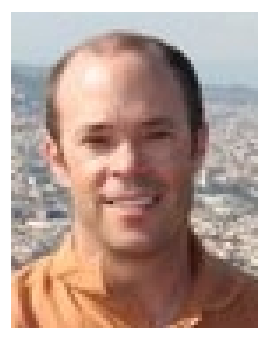

Karl Edquist is an aerospace engineer in the Atmospheric Flight and Entry Systems Branch at NASA Langley Research Center. His areas of expertise are computational aerothermodynamics and aerodynamics, and he has authored or co-authored several papers in these fields. He is the Supersonic Retropropulsion Lead for the Entry, Descent, and Landing Project as well as the Aerothermal Lead for the Mars Science Laboratory entry capsule. He received his B.S. in Aerospace Engineering from the University of Colorado and M.S. in Aerospace Engineering from the University of Maryland. 